\begin{tabular}{|c|c|}
\hline Title & Fungal Decolorization of Microbially Treated Night Soils \\
\hline Author(s) & $\begin{array}{l}\text { HISHINUMA, DAISUKE; MAKABE, A KEMI; TSURUGA, HIDEO; OOI, TOSHIHIKO; KINOSHITA, SHINICHI; } \\
\text { HIRAO, TOMOHIKO }\end{array}$ \\
\hline Citation & $\begin{array}{l}\text { 日本水処理生物学会誌, 37(3), } 123-128 \\
\text { https://doi.org/10.221/swtb.37.123 }\end{array}$ \\
\hline Issue Date & 2001 \\
\hline Doc URL & http:/hdl .handle.net/2115/71463 \\
\hline Rights & 著作権は学会に帰属する \\
\hline Type & article \\
\hline File Information & water 37.3.pdf \\
\hline
\end{tabular}

Instructions for use 


\title{
Fungal Decolorization of Microbially Treated Night Soils
}

\author{
DAISUKE HISHINUMA, AKEMI MAKABE, HIDEO TSURUGA, TOSHIHIKO OOI, \\ SHINICHI KINOSHITA, and TOMOHIKO HIRAO* \\ Division of Molecular Chemistry, Graduate School of Engineering, Hokkaido University \\ /Nishi-8, Kita-13, Kita-ku, Sapporo 060-8628, Japan \\ *Takuma Co. Ltd.,/2-2-23, Kinrakuji-cho, Amagasaki, 660-0806, Japan
}

\begin{abstract}
A fungal strain LM-12 was selected for the decolorization of microbially treated night soils \{filtrate(iv) in Fig. 1$\}$ and it was identified as Penicillium janthinellum. Strain LM12 decolorized $50 \%$ of the color of the medium with $5.0 \mathrm{~g} / \mathrm{l}$ glucose and $0.6 \mathrm{~g} / \mathrm{l}$ ammonium sulfate at $30^{\circ} \mathrm{C}$ for $24 \mathrm{hr}$. Over $50 \%$ decolorization was not attained in any culture conditions tested, but the increase of the mycelial amount enhanced the decolorization rate. So by using repeated replacement culture, the decolorization period was reduced to $2.0 \mathrm{hr}$. The amount of nutrient addition could be reduced in further replacement culture.
\end{abstract}

Key words : decolorization of night soils, night soil decolorization, Penicillium janthinellum, repeated replacement culture

\section{INTRODUCTION}

Recently night soil treatment in villages is carried out in a compact night soil treatment plant. Figure 1 shows a plant in Kamiukena, Matsuyama, and it is composed of following steps: (i ) removal of solids such as sands, metals, and plastics by sedimentation and screening; (ii) treatment by aerobic microbes to remove BOD, COD, nitrogenous compounds, and SS (suspended solid); (iii) microbial denitrification; (iv) membrane filtration to remove microorganisms and SS; (v) addition of chemicals and alkali to promote aggregation of phosphates and colored materials; (vi) membrane filtration to remove aggregates; (vii) decolorization with activated charcoal; (viii) disinfection with hypochlorite addition.

By the operation of this plant some color remains and so the effluent from this system is not discharged without adsorption on active charcoal.

In this study we tried to decolorize the microbially treated night soil (filtrate (iv) in Fig. 1 \} for the cancellation or reduction of the use of activated charcoal. We found a fungal strain to decolorize it to half and optimized the reaction period to $2 \mathrm{~h}$ by the repeated replacement culture.

\section{MATERIALS AND METHODS}

Solution for decolorization The filtrate in step (vi) in Fig. 1 is used for the decolorization to save the amount of active charcoal. The solution after step (viii) can be used, but color of the solution is very faint (less than $\mathrm{A}_{400}$ 0.2), which is not easy to distinguish the color removal by naked eyes in screening of microorganisms. Also after decolorization the solution is expected to return to step (iii) in Fig. 1. The solution at step (ii) or (iii) can be used, but the cleared solution is better because most of microorganisms is removed and we can keep it long during experiments.

The filtrate in step (iv) is obtained from Environmental Sanitation Center, Kami- 


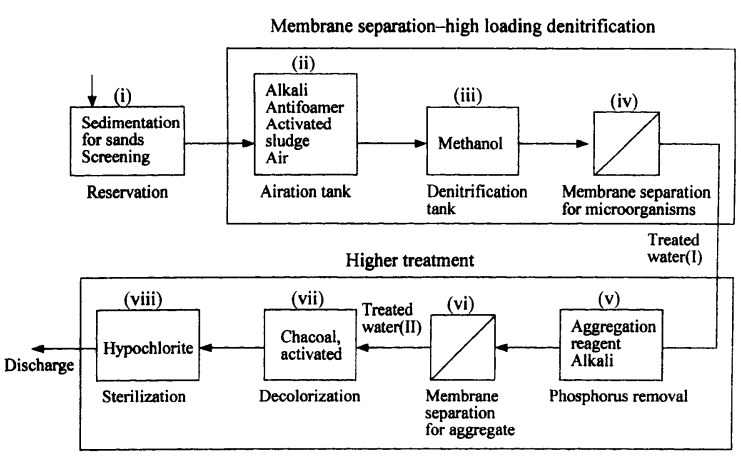

Fig. 1 Flow sheet of human night soil treatment system in a compact plant at Kamiukena, Ehime, Japan.

ukena, Matsuyama which is kept in a cold room. The analytical data of the filtrate: BOD, < $1 \mathrm{mg} / l$; COD, $210 \mathrm{mg} / l$; SS, $<10 \mathrm{mg} / l$ ; total $\mathrm{P}, 100 \mathrm{mg} / l$; total $\mathrm{N}, 18 \mathrm{mg} / l$; color unit, 400; $\mathrm{pH}, 6.9$. As most of BOD and nitrogenous compounds are removed in the filtrate, so $5 \mathrm{~g} / l$ glucose and $0.6 \mathrm{~g} / l$ ammonium sulfate were tentatively added to the filtrate, which was used as a medium.

The initial color of the medium is around 0.8 of absorption at $400 \mathrm{~nm}$.

\section{Decolorization experiments Strain}

LM12 was inoculated into $500-\mathrm{ml}$ conical flask containing $100 \mathrm{ml}$ of the medium from the agar slant and it was incubated at $30^{\circ} \mathrm{C}$ on a rotary shaker.

In a replacement culture mycelia are harvested by filtration apparatus which was sterilized before, and were suspended into the fresh medium. In this experiment we tried to operate under as aseptic conditions as possible. Also the $\mathrm{pH}$ of the preculture was decreased to lower than $\mathrm{pH} 3.0$, which gives more advantage for the replacement culture against microbial contamination.

Measurements The decolorization was determined spectrophotometrically from the absorbance at $400 \mathrm{~nm}$ after filtration of the culture. The mycelial weight was determined after collecting the mycelia from the culture by filtration, washing repeatedly with water, and drying at $80^{\circ} \mathrm{C}$ until a constant weight.

\section{RESULTS AND DISCUSSION}

Absorption spectrum of the culture filtrate The absorption spectrum (320 to $700 \mathrm{~nm}$ ) of the medium gave a monotonous increasing curve toward shorter wave length (Fig. 2A), even before and after the microbial decolorization, which meant the absorption was composed of many colored materials. The absorption of the medium before and after the decolorization at $400 \mathrm{~nm}$ was not affected much by pH 2 to 8 (Fig. 2B), though a little increased in alkaline side. In the experiments we used the $\mathrm{pH}$ range between 2 and 6 , where the absorption did not depend on $\mathrm{pH}$, and so the color is measured without adjusting $\mathrm{pH}$ of the supernatant of medium.
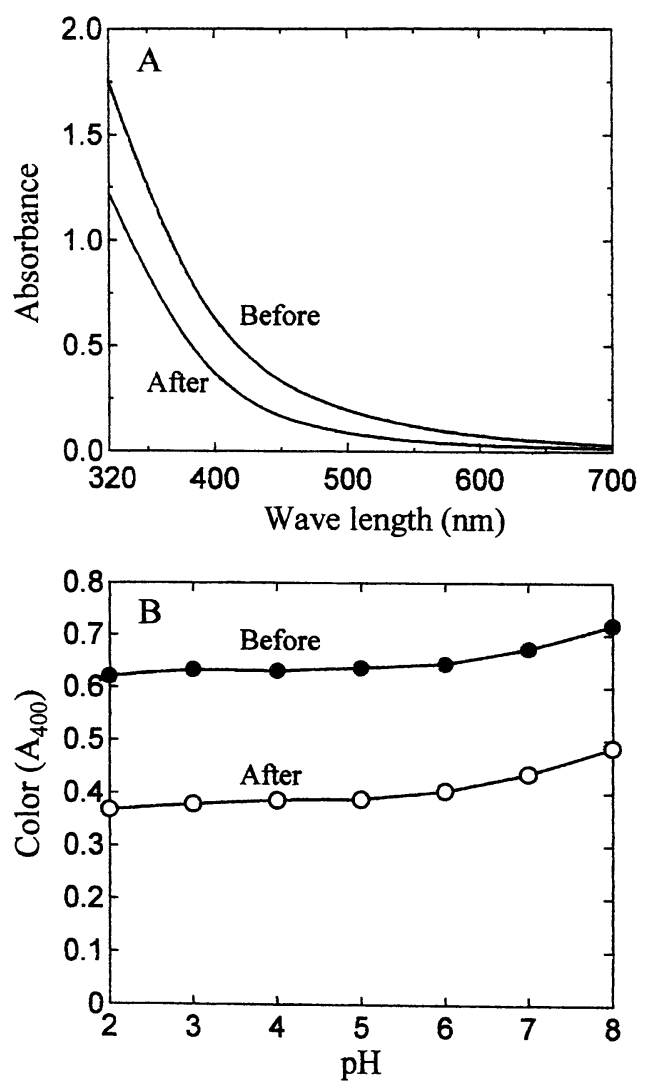

Fig. 2 A Absorption spectra of the medium supernatant containing microbially treated night soil before and after the microbial decolorization. B Effect of $\mathrm{pH}$ on the absorption at $400 \mathrm{~nm}$ before and after the decolorization of the medium. 
Screening of microorganisms for the decolorization One loop from 300 soil samples was inoculated into a test tube containing $5 \mathrm{ml}$ of the medium, and it was incubated on a reciprocal shaker at $30^{\circ} \mathrm{C}$.

After one week, the decolorization was judged by naked eyes, and one loop of which was seeded into the fresh medium. It was cultivated for 5 days, and 25 decolorized samples were seeded into $100-\mathrm{m} l$ conical flasks containing $20 \mathrm{~m} l$ of fresh medium together with 15 stock cultures in our laboratory. They were incubated for 3 days on a rotary shaker and those absorbance at $400 \mathrm{~nm}$ of the supernatant were measured.

A culture to show the highest decolorization, strain LM12, was selected, which had been isolated as a lignin decomposer before. It is used in this study.

The decolorizing activity was not located extracellularly, because the culture filtrate supplemented with the fresh medium was not decolorized at all.

The photo of strain LM12 is shown in Fig. 3. Taxonomical idendification of strain LM-12 was carried out by NCIMB Japan (Shimizu, Japan) and identified as Penicillium janthinellum. $(1,2)$.

The fundamental properties are as follows: hypha has cepta; conidiophore blanches irregularly; double-ring penicilli are composed of blanches, meturoe and fialides; ascus or screlotium is not formed; colony is whity cotton fiber-like until conidiospore

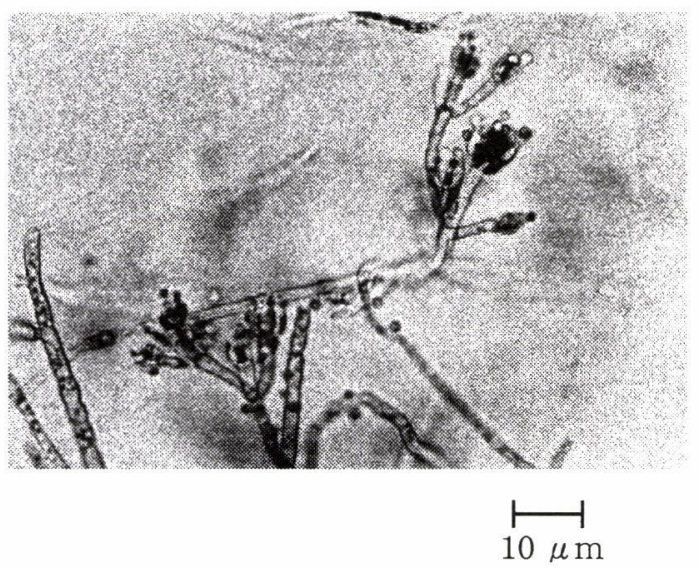

Fig. 3 The photo of strain LM-12. formation and turns to green, then dark green; the reverse side of agar plate is dark orange; spores is mainly globe, rough in surface, and about $3 \mu \mathrm{m}$ in diameter; size of colony is about $6 \mathrm{~cm}$ in diameter on a potatodextrose agar plate after 10-day growth. It was quite rare that $P$. janthinellum was isolated as a decolorizing fungus, because white rot fungi such as Phanerochaete chrysosporium (3), Geotrichum candidum (4), and Coriolus hirsutus (5) were usually found, as decolorizers of azo dyes, molasses, and melanoidine, respectively. It was maintained on malt-extract agar medium.

Optimal culture condition The good decolorization was observed at $30-37^{\circ} \mathrm{C}$ in $2^{-}$ day culture as shown in Fig. 4 , and $30^{\circ} \mathrm{C}$ was used in further experiment.

The best decolorization was observed at initial $\mathrm{pH}$ of 7.0 as shown in Fig. 5, but in further experiments the initial $\mathrm{pH}$ of 6.0 was selected because glucose in the medium gave colored material at $\mathrm{pH} 7.0$ after sterilization.

The decolorizations were high at $2.5 \sim 10.0$ $\mathrm{g} / \mathrm{l}$ glucose concentrations in the medium, the fastest at $5.0 \mathrm{~g} / l$ glucose (Fig. 6), and this concentration was used in further experiments. The strain could not decolorize the medium without the addition of glucose.

The decolorizations were high at $0.6 \sim 2.4$ $\mathrm{g} / \mathrm{l}$ ammonium sulfate concentration (Fig. 7), the fastest at $0.6 \mathrm{~g} / \mathrm{l}$ ammonium sulfate, and this concentration was used in further

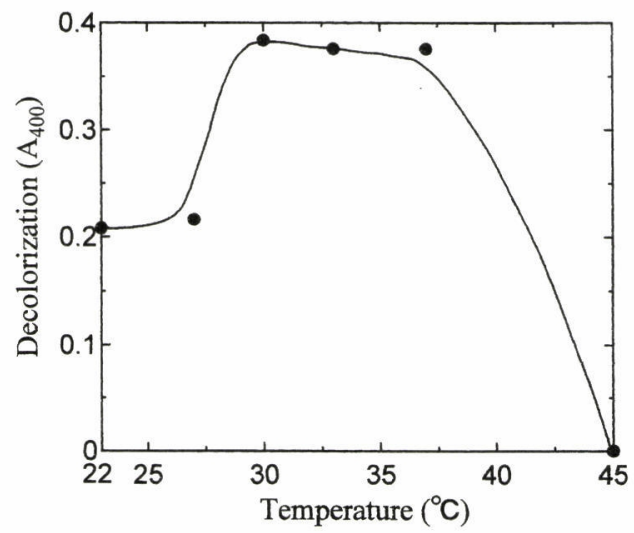

Fig. 4 Effect of incubation temperature on the decolorization of the medium using microbially treated night soils by strain LM12 for 2 days. 
experiments. Strain LM-12 could not decolorize without the addition of ammonium sulfate.

The time course of the decolorization under the optimal condition was shown in Fig. 8.

The growth became active after $12 \mathrm{~h}$ and continued to grow untill $24 \mathrm{~h}$. The $\mathrm{pH}$ began to decrease sharply after $12 \mathrm{~h}$ and reached to $\mathrm{pH} 3.0$ at $16 \mathrm{~h}$. The decolorization also started at $12 \mathrm{~h}$, and after $24 \mathrm{~h} 50 \%$ of decolorization was attained.

Decolorization degree After the incubation for $24 \mathrm{~h}, 5.0 \mathrm{~g} / l$ glucose and $0.6 \mathrm{~g} / \mathrm{l}$ ammonium sulfate were added to the culture and it was further incubated for more $24 \mathrm{~h}$.

The cell mass increased, but the

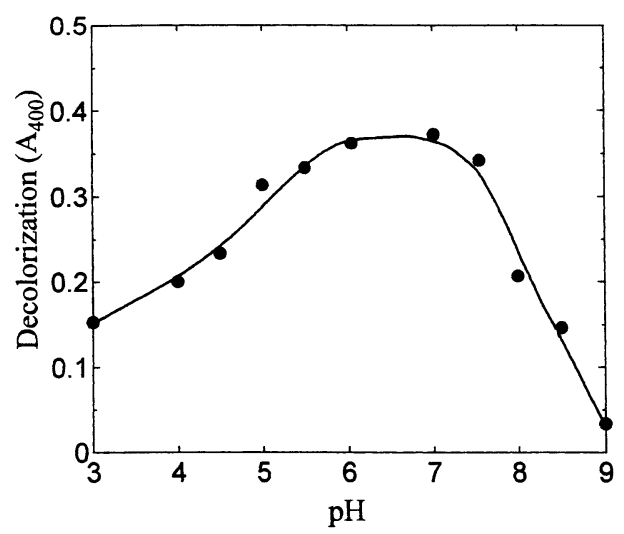

Fig. 5 Effect of the initial pH on the decolorization of the medium by strain LM12 for 2 days.

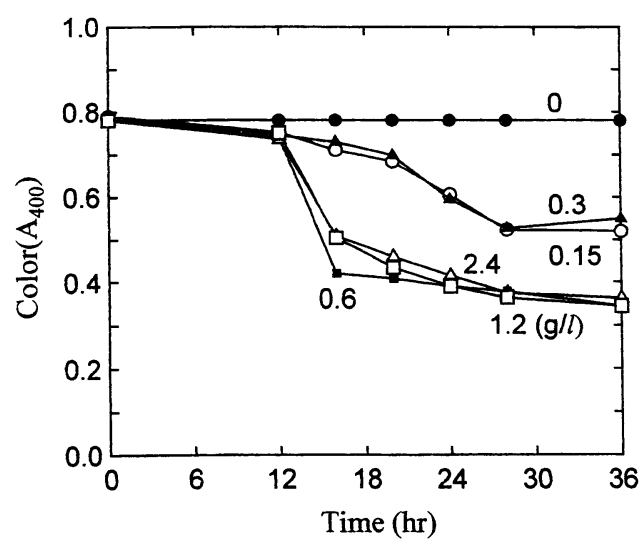

Fig. 7 Time courses of the decolorization of the medium by the addition of different concentration of ammonium sulfate by strain LM12. decolorization did not proceed any more (data were not shown).

The culture filtrate was recovered after 24 $\mathrm{h}$, to which glucose and ammonium sulfate at 5.0 and $0.6 \mathrm{~g} / l$, respectively, were added, LM12 was inoculated, and it was incubated for another $24 \mathrm{~h}$. Strain LM-12 could grow as well as before, but the decolorization did not proceed any more (data were not shown).

To check the effect of amount of mycelia on the decolorization, the mycelia were harvested by filtration from one, two, or four flasks of 24-h culture, and they were suspended to fresh media to give different amounts of mycelia (1-4 folds), which were incubated for more $24 \mathrm{~h}$, but the

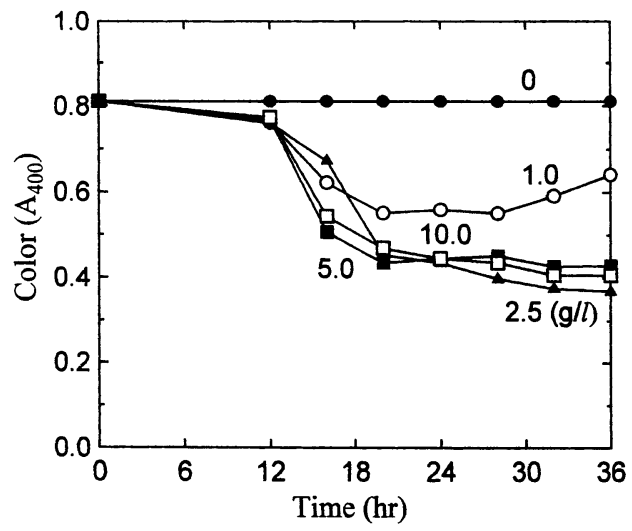

Fig. 6 Time courses of the decolorization of the medium by the addition of different concentration of glucose by strain LM12.

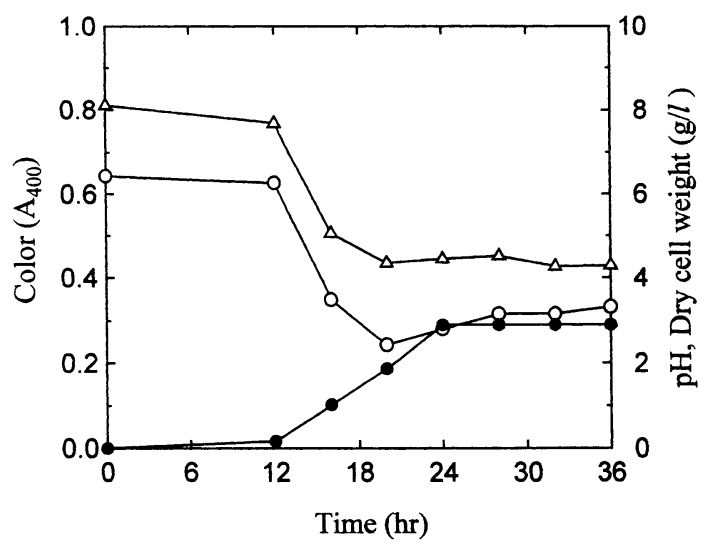

Fig. 8 The decolorization of the medium under the optimal culture condition. Symbols: $\triangle$, color; $\bigcirc, \mathrm{pH}$; $\bigcirc$, dry cell weight. 
decolorization were about $50 \%$, however, the decolorization periods were reduced to $3.5 \mathrm{~h}$ by the replacement culture ( 1 fold) from $24 \mathrm{~h}$ in the previous batch experiments. And also the increases of mycelial amount to 2 and 4 folds reduced the decolorization period to 2.0, and $1.5 \mathrm{~h}$, respectively (Fig. 9). This meant that some part of colored components in the filtrate were resistant to further decolorization by strain LM-12. However, the maximum decolorization rates were 0.09 , 0.15 , and $0.26 \Delta \mathrm{A}_{400} / \mathrm{h}$, with 1,2 , and 4 folds of mycelial amount, respectively, and so decolorization periods were also reduced in the same order. These results meant that the higher amount of mycelia promoted the decolorization rate very much and we should use the higher mycelial amount in the decolorization.

\section{Decolorization by replacement culture}

So to obtain higher mycelial amount, the strain was precultured for $48 \mathrm{~h}$ with intermittent additions of nutrients (5.0 glucose and $0.6 \mathrm{~g} / \mathrm{l}$ ammonium sulfate) at 24 and $36 \mathrm{~h}$, respectively. The mycelia were harvested by filtration from the preculture, suspended in the fresh medium, and incubated for $2 \mathrm{~h}$. The decolorization attained to a steady level, then the mycelia were harvested, used for the further rounds of replacement cultures at 2 h-interval as

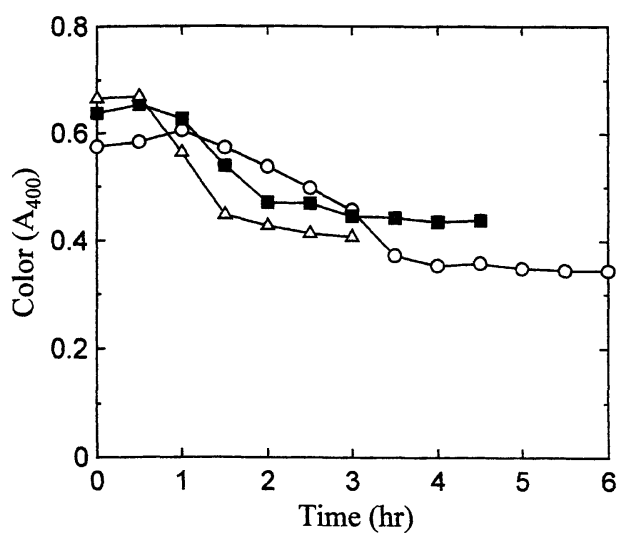

Fig. 9 Effect of cell mass in the replacement culture on the decolorization. The different amounts of mycelia were prepared by harvesting mycelia from different numbers of flasks precultured for $24 \mathrm{~h}$.

Symbols (relative call mass): 0,1 fold; $\square, 2$ folds; $\triangle, 4$ folds. shown in Fig. 10. This experimental results showed that the replacement culture worked well for the reduction of decolorization period.

In the next experiment 24-h culture was used as a preculture without obtaining higher mycelial amount in the first round of replacement culture. So the culture was replaced when the decolorization attained to a steady level as shown in Fig. 11. The decolorization time in the first culture was $4.5 \mathrm{~h}$, that in the second was $3.0 \mathrm{~h}$, those in the third and fourth was $2.5 \mathrm{~h}$, and those after the fifth were $2.0 \mathrm{~h}$. This 2 -h decolorization was attained for at least following 10 replacement cultures without using 48-h preculture. This reaction system would be very convenient for the scale-up, because one replacement culture takes only 2 $h$ and replacement culture could be operated by natural sedimentation of mycelia, removal of supernatant, and addition of the fresh medium without filtration, and mixing of mycelia in the next decolorization process.

Though a constant amount of $5 \mathrm{~g} / \mathrm{l}$ glucose and $0.6 \mathrm{~g} / \mathrm{l}$ ammonium sulfate addition into the replacement culture was employed, but such much amounts of nutrient additions may not always be necessary and the amount of nutrient may be reduced in the replacement culture. So the replacement culture was carried out with addition of

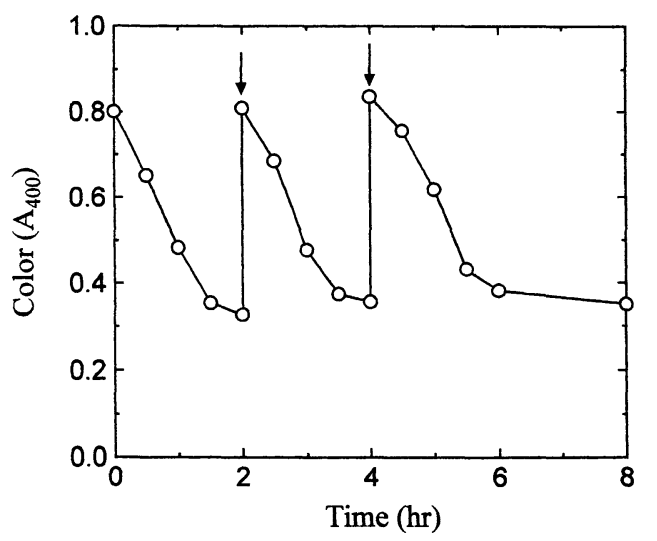

Fig. 10 The replacement culture by using higher amounts of mycelia. The higher amounts of mycelia were prepared from the precultures, which was incubated for $48 \mathrm{~h}$ with twice additions of the nutrients. 
different amounts of glucose and ammonium sulfate. The standard nutrient concentration is composing of $5.0 \mathrm{~g} / \mathrm{l}$ glucose and $0.6 \mathrm{~g} / \mathrm{l}$ ammonium sulfate. The first replacement cultures with addition of 10 and $20 \%$ of the standard nutrient did not give sufficient decolorization, and that with $40 \%$ nutrient addition gave a little less decolorization than that with the standard nutrient addition as shown in Fig. 12. But the second replacement culture with $40 \%$ nutrient addition gave the same decolorization as that with the standard nutrient addition. So it may be possible to reduce the addition of nutrient more in prolonged replacement cultures.

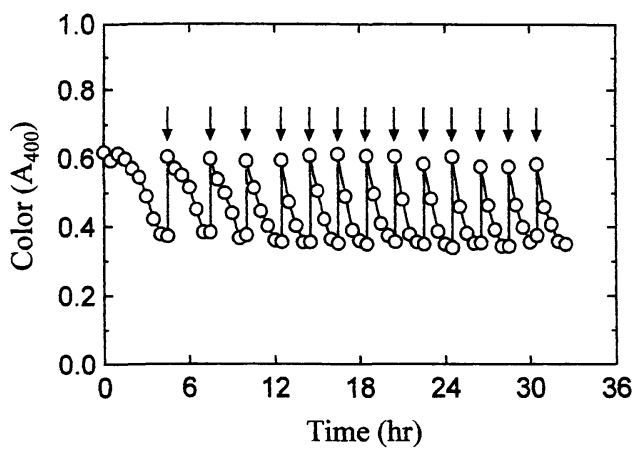

Fig. 11 Repeated replacement culture. The seed was precultured for 24-h and each replacement culture was carried out when the decolorization attained at a steady level $(50 \%$ decolorization).

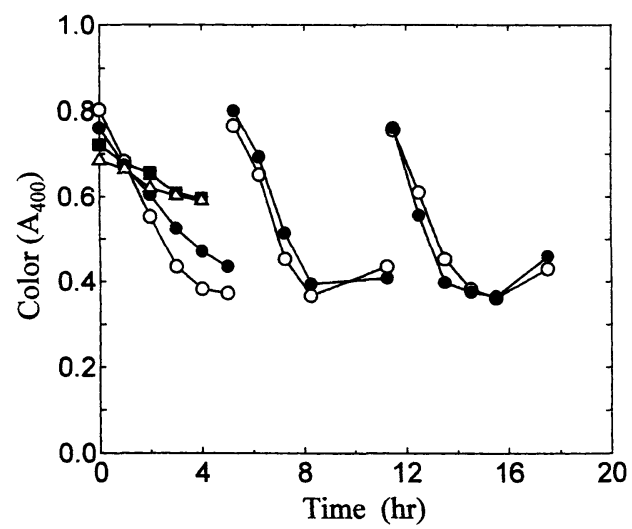

Fig. 12 Addition of reduced amounts of nutrients in replacement culture.

Symbols (nutrient addition) $: \bigcirc$, standard (100\%, $5 \mathrm{~g} / /$ glucose and $0.6 \mathrm{~g} / \mathrm{l}$ ammonium sulfate) ;, $40 \% ; \triangle, 20 \% ; \square, 10 \%$ of the standard.

\section{CONCLUSION}

We selected $P$. janthinellum LM12 as a decolorizer of microbially treated night soil \{filtrate in step (iv) in Fig. 1\} with addition of $5 \mathrm{~g} / l$ glucose and $0.6 \mathrm{~g} / l$ ammonium sulfate, which decolorized $50 \%$ of the filtrate within 2 day culture. We optimized culture conditions for the decolorization, where the reaction period was reduced to $2 \mathrm{~h}$ by replacement culture but more than $50 \%$ of the decolorization was not attained. In a prolonged replacement culture the amount of glucose and ammonium sulfate addition is suggested to be reduced.

\section{REFERENCES}

1 ) Raper, K. B. and Thom, C. : A manual of the Penicillia., p. $120-125$, p. 299-303, and p. 318-322, Williams \& Wilkins (1949)

2 ) Udagawa, S. and Tsubaki, K. : Illustrated book of fungi (in Japanese), p. 1076-1081 and p. 1099-1100 (1978)

3 ) Spadaro, j. T., Gold, M. H., and Renganathan, V. : Degradation of azo dye by the lignin-degrading fungus Phanerochaete chrysosporium. Appl. Environ. Microbiol., 58, 2397-1401 (1992)

4 ) Kim, S. J. and Shoda, M. : Batch decolorization molasses by suspended and immobilized fungus of Geotrichum candidum Dec. 1. J. Biosci. Bioeng., 88, 577-581 (1999)

5 ) Miyata, N., Mori, T., Iwahori, K., and Fujita, M. : Microbial decolorization of melanoidine-containing wastewater: combined use of activated sludge and the fungus Coriolus hirsutus. J. Biosci. Bioneng., 89, 145-150 (2000)

(Submitted 2001. 5. 7)

(Accepted 2001. 6. 20) 